Jurdimas (Jurnal Pengabdian Kepada Masyarakat) Royal

Vol. 2 No. 1, Jan 2019, hlm. $13-18$

ISSN 2614-7912 (Print)

DOI: https://doi.org/10.33330/jurdimas.v2i1.280

ISSN 2622-3813 (Online)

Available online at https://jurnal.stmikroyal.ac.id/index.php/jurdimas

\title{
DONGENG SEBAGAI STIMULAN AWAL PENINGKATAN MINAT BACA BAGI SISWA PAUD BUNDA HAJAR JATINANGOR
}

\author{
Vincentia Tri Handayani, M. Hum*, Asri Afsari, M. Hum., Ferli Hasanah, M.Hum \\ Fakultas Ilmu Budaya Universitas Padjadjaran \\ email : v.tri@unpad.ac.id
}

\begin{abstract}
The decline in interest in reading among the younger generation is caused by, among other things, being distracted from the attention and leisure time of young people in social media activities. In addition, to get the information they need, they can get it only by using their smartphone. Seeing the situation that concerns this, the effort to stimulate literacy education must be instilled from the beginning of time. This PPM aims to increase reading interest of Bunda Hajar Dusun Sukanegla PAUD students, Desa Hegarmanah, Jatinangor, Sumedang. In order to be interesting, the delivery of counseling and educational activities is carried out using the storytelling method. The results obtained, children are more interested in listening, able to survive listening and can answer questions about fairy tales delivered.
\end{abstract}

Keywords: literacy education, fairy tales, early childhood education

ABSTRAK : Menurunnya minat membaca di kalangan generasi milenial disebabkan oleh antara lain teralihnya perhatian dan luang waktu anak muda pada kegiatan media sosial. Selain itu, untuk memperoleh informasi yang mereka butuhkan, mereka bisa mendapatkan secara instan hanya dengan melalui telepon genggam. Melihat keadaan yang memprihatikan ini, maka upaya menstimulasi edukasi literasi harus ditanamkan sejak usia dini. Pengabdian Pada Masyarakat (PPM) ini bertujuan meningkatkan minat baca dengan sasaran siswa PAUD Bunda Hajar Dusun Sukanegla Desa Hegarmanah Jatinangor Kabupaten Sumedang. Agar menarik, penyampaian penyuluhan dan kegiatan edukasi dilaksanakan dengan menggunakan metode mendongeng. Hasil yang diperoleh, anak-anak lebih tertarik mendengarkan, mampu bertahan menyimak dan dapat menjawab pertanyaan seputar dongeng yang disampaikan.

Kata kunci: edukasi literasi, dongeng, pendidikan anak usia dini

PENDAHULUAN

Kegiatan Pengabdian Pada Masyarakat (PPM) ini merupakan upaya dari tim pelaksana pada khususnya dan Universitas Padjadjaran pada umumnya untuk menemukan persoalan nyata yang ada di masyarakat, terutama yang berada di sekitar kampus Universitas Padjadjaran Jatinangor, yaitu masih rendahnya motivasi dan minat baca di kalangan generasi muda.

Kegiatan ini mencoba
menawarkan solusi-solusi untuk
permasalahan tersebut, yaitu berupa
peningkatan motivasi dan minat baca
di kalangan generasi muda, melalui
kegiatan mendongeng yang disertai
dengan beragam kegiatan edukatif
kreatif lainnya, serta penyediakan
media kegiatan yang dapat
digunakan demi tercapainya tujuan
kegiatan ini. Kegiatan PPM ini
adalah mengupayakan peningkatan
minat baca di kalangan anak-anak


Jurdimas (Jurnal Pengabdian Kepada Masyarakat) Royal

Vol. 2 No. 1, Jan 2019, hlm. 13 - 18

ISSN 2614-7912 (Print)

DOI: https://doi.org/10.33330/jurdimas.v2i1.280

ISSN 2622-3813 (Online)

Available online at https://jurnal.stmikroyal.ac.id/index.php/jurdimas

usia 4-6 tahun yang distimulasi melalui pembacaan dongeng yang merupakan bentuk tradisi budaya lisan.

Permasalahan

yang

teridentifikasi adalah

1. rendahnya pendapatan keluarga di sekitar wilayah PAUD Bunda Hajar menyebabkan pula rendahnya kesadaran akan pendidikan bagi anak-anak, sementara lokasinya berdekatan dengan lingkungan pendidikan,

2. minat baca yang sangat kurang karena keterbatasan finansial dan fasilitas yang ada di PAUD Bunda Hajar.

Penelitian berjudul Sastra dan Minat Baca pada Siswa SMAN Tanjungsari (Som dkk, 2006) menggungkapkan beberapa fakta yang menunjukkan betapa rendahnya minat baca di kalangan responden. Dari lima puluh orang siswa, hanya satu orang $(2 \%)$ yang menyatakan memiliki kebiasaan membaca setiap hari. Hanya ada empat orang (8\%) yang menyatakan bahwa membaca merupakan kegiatan yang mereka lakukan saat waktu senggang mereka, sementara tiga puluh siswa lainnya $(62 \%)$ lebih memilih untuk menonton televisi. Hal ini memperlihatkan bahwa membaca belum menjadi kegiatan yang biasa dilakukan oleh para siswa.

Berdasarkan keprihatinan atas rendahnya motivasi dan minat baca di kalangan generasi muda dan kesadaran akan pentingnya membaca bagi perkembangan dan kemampuan individu serta kehendak untuk berperan aktif dalam memajukan masyarakat, khususnya mereka yang ada di lingkungan sekitar kampus
Universitas Padjadjaran Jatinangor, maka dilakukan kegiatan Pengabdian Kepada Masyarakat (Intan dkk, 2015) yang bertujuan untuk meningkatkan minat baca siswa. Kegiatan tersebut dilakukan bersama pihak pengelola PAUD (Pendidikan Anak Usia Dini) Bunda Hajar dengan publik sasaran siswa yang bersekolah di sana yang berlokasi di Jatinangor.

Sejalan dengan kegiatan yang telah berjalan, PPM ini menawarkan jenis kegiatan lain, yaitu mendongeng dan penyuluhan ketrampilan. Mendengarkan dongeng merupakan sebuah aktivitas yang penting dalam tumbuh kembang seorang anak. Hal ini dijelaskan oleh Rolland Cause dalam bukunya yang berjudul Qui lit petit lit toute la vie, bahwa dongeng merupakan permainan, suatu hal yang sangat penting dalam pembentukan individu. "Saat mendengarkan dongeng, seorang anak mengidentifikasikan dirinya dengan tokoh-tokoh yang hadir, ia turut merasakan kesenangan dari sebuah petualangan ketegangan atau fantasi dan impian. Sejalan dengan pembentukan identitas 'aku' melalui proses identifikasi terhadap tokoh utama serta melalui proses mendengarkan yang berulang-ulang, anak akan merasakan kesenangan dari sebuah permainan. Keinginan yang menjawab kebutuhan : kebahagiaan yang terbarukan melalui bacaan, secara perlahan mengembangkan keinginan untuk terus mendengarkan cerita seru lainnya, dongeng-dongeng menakjubkan lainnya atau, tergantung umur si anak, untuk membaca cerita-cerita lainnya (2005 
Jurdimas (Jurnal Pengabdian Kepada Masyarakat) Royal

Vol. 2 No. 1, Jan 2019, hlm. 13 - 18

ISSN 2614-7912 (Print)

DOI: https://doi.org/10.33330/jurdimas.v2i1.280

ISSN 2622-3813 (Online)

Available online at https://jurnal.stmikroyal.ac.id/index.php/jurdimas

:20)

satu $\begin{gathered}\text { Dongeng merupakan salah } \\ \text { bentuk folklor. James }\end{gathered}$ Danandjaja (2002:2) mendefinisikan folklor sebagai bagian kebudayaan suatu kolektif, yang tersebar dan diwariskan turun menurun, di antara kolektif macam apa saja, secara tradisional dalam versi yang berbeda, baik dalam bentuk lisan maupun contoh yang disertai dengan gerak isyarat atau alat pembantu pengingat. Folklor juga menyimpan keragaman sastra daerah yang mendukung proses pembangunan jati diri dan budaya lokal. Dongeng merupakan cerita khayalan atau cerita yang tidak benar-benar terjadi, biasanya bersifat menghibur dan mengandung nilai pendidikan. Cerita yang dikarang dan diceritakan kembali secara berulangulang oleh orang-orang. Biasanya dongeng dibuat karena terinspirasi dari suatu peristiwa.

Kesenangan yang dirasakan saat mendengarkan dongeng kemudian akan menumbuhkan "perilaku pembaca yang terwujud dalam sebuah kontrak berupa bacaan personal, yang elemen pertamanya berhubungan dengan pemuasan kebutuhan individual dalam kerangka menemukan selera dan minat serta pertanyaan pribadi (Poslaniec \& Houyel, 2000: 7). Hal ini menunjukkan bahwa mendongeng dapat menjadi sarana yang efektif dalam menumbuhkan serta meningkatkan minat baca. Kegiatankegiatan yang akan dilakukan menawarkan solusi dan pemecahan masalah edukasi literasi bagi masyarakat yang ada di sekitar Universitas Padjadjaran. Hal ini merupakan kepedulian dan kontribusi institusi Perguruan Tinggi dalam pembangunan bangsa.

Salah satu instansi pendidikan yang ada di sekitar kampus Universitas Padjadjaran adalah PAUD Bunda Hajar di dusun Sukanegla yang terletak kurang lebih 3 kilometer dari kampus Jatinangor. Pendidikan Anak Usia Dini (PAUD) adalah pendidikan yang memberikan pengasuhan, perawatan, dan pelayanan pada anak usia lahir samapai 6 tahun. Pendidikan anak usia dini merupakan upaya pembinaan yang dilakukan melalui pemberian rangsangan pendidikan untuk membantu pertumbuhan dan perkembangan jasmani serta rohani agar anak dapat memiliki kesiapan dalam memasuki sekolah dasar dan kehidupan berikutnya. Hal tersebut terdapat dalam Peraturan Menteri Pendidikan Nasional Nomor 58 Tahun 2009 Tanggal 17 September 2009 tentang Standar Pendidikan Anak Usia Dini.

\section{METODE}

Masalah minimnya minat baca pada usia dini dan melunturnya budaya mendongeng diatasi dengan memperkenalkan dongeng itu sendiri kepada siswa-siswa PAUD Bunda Hajar. Upaya peningkatan edukasi literasi dan menanamkan kesenangan membaca ini dilakukan melalui metode mendongeng. Dalam PPM ini digunakan metode penyuluhan dan mendongeng dari pemateri, serta bagi siswa-siswa PAUD digunakan metode menyimak dan menyimpulkan.

Menurut psikolog Monica

Sulistiawati

(https://edukasi.kompas.com/read/) 


\section{Jurdimas (Jurnal Pengabdian Kepada Masyarakat) Royal}

Vol. 2 No. 1, Jan 2019, hlm. 13 - 18

ISSN 2614-7912 (Print)

DOI: https://doi.org/10.33330/jurdimas.v2i1.280

ISSN 2622-3813 (Online)

Available online at https://jurnal.stmikroyal.ac.id/index.php/jurdimas

mendongeng juga memiliki banyak manfaat lain, diantaranya:

1. Perkembangan kognitif Untuk dapat memperluas pengenalan objek seorang anak, pada saat mendongeng, gunakan alat peraga misalnya buku bergambar. Dengan begitu, anak bisa melihat bentuk dari tokoh yang diceritakan dalam dongeng. Selain itu, dongeng juga dapat menambah wawasan. Melalui kisah-kisah dongeng, anak mendapatkan berbagai informasi. Anak juga dapat mempelajari sebab akibat serta belajar menganalisa. Melalui dongeng juga, pemikiran anak menjadi lebih baik, lebih kritis dan cerdas. Anak juga bisa memahami hal mana yang perlu ditiru dan tidak boleh.

2. Perkembangan sosial dan emosional dari kegiatan mendongeng, kita bisa menyelipkan ajaran norma-norma seperti sosial, agama dan sopan santun. Tidak hanya teori, tapi ajarakan secara langsung bagaimana melakukannya. "Anakanak cenderung mempunyai kesulitan dalam mempelajari nilainilai moral dalam kehidupan. Dengan dongeng anak-anak maka kita bisa memberikan contoh melalui tokoh dalam cerita yang kita dongengkan," jelasnya seperti dikutip dari laman Sahabat Keluarga Kementerian Pendidikan dan Kebudayaan.

3. Memperat ikatan anak dan orang tua Kesibukan orang tua kerap kali membuat komunikasi anak dan orang tua kurang intensif. Dengan mendongeng, orang tua berdekatan secara intim, komunikasi efektif pun berjalan dengan baik.

4. Mengembangkan daya imajinasi Dunia anak adalah dunia imajinasi. Anak memiliki dunia sendiri dan tak jarang mereka berbicara dengan teman khayalannya. Dengan daya imajinasi yang masih sangat bagus ini, maka orang tua harus bisa mengarahkannya ke arah yang positif dan tetap terkontrol. Anak yang kurang imajinasi bisa berakibat pada pergaulan yang kurang, sulit bersosialisasi atau beradaptasi dengan lingkungan yang baru.

5. Meningkatkan keterampilan berbahasa Dongeng merupakan stimulasi dini yang mampu merangsang keterampilan berbahasa pada anak-anak. Kisahkisah dongeng yang mengandung cerita positif tentang perilaku membuat anak-anak menjadi lebih mudah dalam menyerap tutur kata yang sopan. Menurut Monica, dari segi perkembangan bahasa, anak yang sering mendengarkan orang tuanya mendongeng maka perkembangan linguistiknya lebih meningkat dibandingkan anak yang tidak pernah didongengkan.

6. Membangkitkan minat baca Dengan memberikan cerita dongeng pada anak-anak, mereka akan tertarik dan penasaran untuk mencari tahu. Inilah dimana keingian untuk membaca semakin meningkat.

\section{HASIL DAN PEMBAHASAN}

Peningkatan minat baca hendaknya dimulai sejak usia dini, untuk menanamkan kebiasaan. Salah 
Available online at https://jurnal.stmikroyal.ac.id/index.php/jurdimas

satu cara meningkatkan minat baca adalah dengan cara mendongeng. Budaya mendongeng untuk anak saat akan tidur sudah mulai luntur dewasa ini. Padahal dengan mendongeng, kita dapat mengenalkan nilai-nilai atau norma-norma dalam berkehidupan di bawah alam sadar anak-anak. Melalui karakter yang ada dalam dongeng, anak-anak diajarkan tentang nilai kebaikan, rasa empati, tolong menolong dan sebagainya. Dongeng adalah budaya lisan yang disampaikan secara turun temurun yang berkembang di masyarakat. Sebagai bentuk folklore, dongeng dapat membantu anak-anak untuk berimajinasi. Dengan imajinasi anak-anak mampu berpikir kreatif dan belajar berkomunikasi dengan orang lain.

Dongeng juga dapat menstimulasi keinginan anak untuk membaca. Mereka akan tertarik dengan dongeng yang lain setelah mendengar sebuah dongeng. Pada kesempatan ini kita dapat mengenalkan anak-anak buku-buku cerita yang berisi dongeng, dengan begitu diharapkan akan menjadi suatu habituasi membaca. Setelah mendengar satu dongeng, seringkali anak kemudian tertarik untuk mendengar dongeng yang lain. Kita dapat menggunakan kesempatan ini untuk memperkenalkan buku sebagai salah satu "teman" yang mengasyikkan. Sering-sering mengajak anak ke toko dan membiarkan ia memilih bukunya sendiri, akan semakin membantu menumbuhkan minat baca pada anak. Manfaat lain dari mendongeng adalah membantu anak-anak memperkaya kosakata yang mereka miliki. Selain itu, mendongeng secara tidak langsung menjalin hubungan orang tua dengan anak menjadi sangat dekat.

Untuk

merealisasikan

peningkatan minat baca melalui metode mendongeng, maka telah disusun sejumlah kegiatan yang dilakukan oleh mahasiswa KKN dan dosen pelaksana PPM. Mahasiswa terlibat dalam kegiatan belajar mengajar di PAUD Bunda Hajar dengan menyampaikan cerita-cerita rakyat yang dilanjutkan dengan membahas nilai-nilai yang terkandung dalam cerita tersebut. Kemudian diakhiri dengan pemberian kuis untuk mengawal daya simak siswa.

Pada saat pelaksanaan PPM, dosen pendamping lapangan atau dosen pelaksana PPM memberikan materi penyuluhan mengenai pentingnya membiasakan membaca kepada orang tua siswa. Lalu, ditampilkan video dongeng yang berasal dari tanah Pasundan Sakadang Kuya, Sakadang Monyet dan dongeng dari Perancis Le petit chaperon rouge atau Gadis Berkerudung Merah. Mahasiswa pun menampilkan cerita fabel dengan menggunakan media wayang kertas buatan. Setiap akhir pemutaran film atau pertunjukan wayang kertas, dilakukan sesi tanya jawab untuk melihat daya simak dan ketertarikan siswa. Ternyata mereka sangat senang dan dapat menjawab semua pertanyaan. Kegiatan diakhiri dengan pemberian buku cerita dongeng kepada siswa sebagai stimulan peningkatan minat baca dan pengenalan dongeng-dongeng yang ada di Indonesia, serta memberikan buku-buku cerita sebagai bantuan pengadaan perpustakaan di PAUD 
Jurdimas (Jurnal Pengabdian Kepada Masyarakat) Royal

Vol. 2 No. 1, Jan 2019, hlm. 13 - 18

ISSN 2614-7912 (Print)

DOI: https://doi.org/10.33330/jurdimas.v2i1.280

ISSN 2622-3813 (Online)

Available online at https://jurnal.stmikroyal.ac.id/index.php/jurdimas

Bunda Hajar yang diharapkan dapat dikembangkan menjadi tempat budaya literasi di masyarakat sekitar.

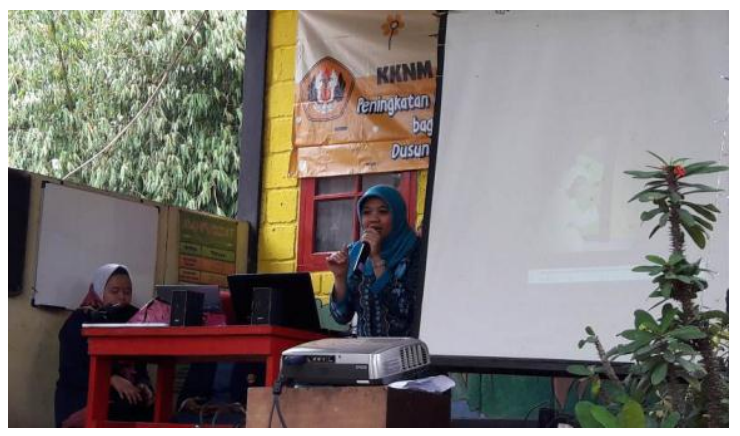

Gambar 1. Penyampaian Materi Dongeng oleh Dosen Pelaksana PPM

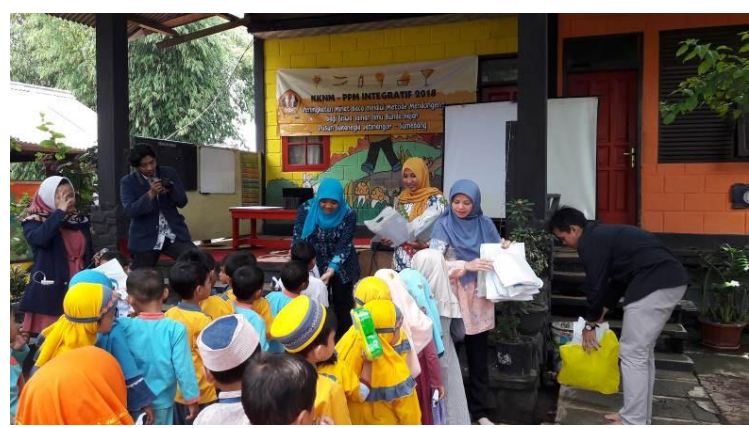

Gambar 2. Pembagian Buku

Dongeng sebagai Stimulan

Peningkatan Minat Baca

\section{SIMPULAN}

Melihat respon siswa-siswa
PAUD yang sangat antusias
menjawab pertanyaan seputar dongeng yang disampaikan, diperlukan kegiatan yang sifatnya berkelanjutan dan rutin dilaksanakan. Saat ini, BEM Universitas Padjadjaran memiliki kerja sama dengan PAUD Bunda Hajar dalam bentuk kegiatan belajar yang dinamakan Taman Ilmu.

Dekatnya jarak lokasi kegiatan dengan kampus tim pelaksana diharapkan dapat memudahkan pelaksanaan kegiatan dan pemantauan hasil-hasil program. Selain itu, program kegiatan upaya peningkatan minat baca melalui metode mendongeng bagi siswa PAUD Bunda Hajar Desa Sukanegla Kecamatan Jatinangor Kabupaten Sumedang sangat potensial untuk dikembangkan.

\section{DAFTAR PUSTAKA}

Causse, Rolande. (2005). Qui lit petit lit toute la vie. Paris: Albin Michel.

Harususilo, Yohanes Rnggar. (2018). 6 Manfaat Mendongeng untuk Anak. melalui https://edukasi.kompas.com/rea d/

Intan, Tania, dkk. (2015). Peningkatan Minat Baca Siswa PAUD Bunda Hajar melalui Keterampilan Menyimak, Membaca, Berbicara, dan Menulis. Laporan Pengabdian Kepada Masyarakat. Jatinangor : Fakultas Ilmu Budaya, Universitas Padjadjaran.

Danandjaja, James. (2002). Folklor Indonesia: Ilmu gosip, dongeng, dan lain-lain.Jakarta: Grafiti.

Poslaniec, Christian \& Houyel, Christine. (2000). Activités de lecture à partir de la littérature de jeunesse. Paris : Hachette.

Som, Witakania S. dkk. (2006). Sastra dan Minat Baca pada Siswa SMAN Tanjungsari. Laporan Penelitian DIPA PNBP. Jatinangor : Fakultas Sastra, Universitas Padjadjaran. 